GU J Sci, Part C, 6(2): 319-335 (2018)

Gazi Üniversitesi
Fen Bilimleri Dergisi
PART C: TASARIM VE TEKNOLOJI
dergipark.gov.tr/http-gujsc-gazi-edu-tr

\title{
Oksitleyiciye su buharı ilavesinin kok fırını gazı yanma davranışlarına olan etkisinin sayısal olarak incelenmesi
}

\author{
Serhat KARYEYEN ${ }^{1}$, Mustafa ILLBAŞ ${ }^{1 *}$ \\ ${ }^{I}$ Gazi Üniversitesi, Teknoloji Fakültesi, Enerji Sistemleri Mühendisliği Bölümü, 06500, Teknikokullar Yenimahalle/ANKARA
}

\begin{abstract}
$\ddot{\mathbf{O z}}$
Makale Bilgisi

Başvuru: 10/11/2017

Düzeltme: $13 / 12 / 2017$

Kabul: 26/12/2017

Anahtar Kelimeler

Yanma

Kok firını gazı

Su buharl

$H A D$

Bu çalıșma kapsamında, oksitleyiciye su buharı ilavesinin kok firını gazı yanma davranışlarına olan etkileri sayısal olarak araştırılmıştır. Çalışmada, ticari bir hesaplamalı akışkanlar dinamiği programı olan Ansys Fluent yazılımı kullanılmıştır. Oksitleyici olarak kuru havanın kullanıldığı tahmin sonuçları deneysel sonuçlarla karşılaştırılmış ve sonuçların deneysel verilerle oldukça iyi bir uyum içerisinde oldukları trend ve değerler bakımından belirlenmiştir. k-E standard türbülans modeli, türbülans modeli olarak seçilmiş olup, üç boyutlu sayısal modellemeler için PDF / Mixture Fraction yanma modeli ve P-1 radyasyon modeli kullanılmıştır. Yapılan tahmin sonuçlarına göre, oksitleyici bünyesine ilave edilen su buharının kok firını gazı için elde edilen sıcaklık değerlerini düşürdüğü belirlenmiştir. Sonuçlar emisyon bakımından değerlendirildiğinde, yapılan su buharı ilavesi ile birlikte NOX emisyonlarının önemli derecede, $\mathrm{CO} 2$ emisyonlarının ise bir miktar azaldığı tespit edilirken $\mathrm{CO}$ emisyonlarının ise bir miktar arttığı ortaya konulmuştur. Sonuç olarak, alternatif bir yakıt olarak kok firını gazı kullanımının yol açtı̆̆ 1 yüksek NOX probleminin oksitleyici bünyesine su buharı ilavesi ile büyük ölçüde aşılabildiği sonucuna varılmıştır.
\end{abstract}

Keywords

Combustion

Coke oven gas

Steam

$C F D$

\section{Numerical investigation of steam addition into the oxidizer on combustion behaviours of coke oven gas}

\begin{abstract}
The effects of steam addition into the oxidizer on combustion behaviours of coke oven gas has been numerically investigated within the present study. Ansys Fluent that is a commercial computational fluid dynamics code has been used in the study. The predictions in which air have been used as oxidizer have been compared with the experimental results and it has been determined that the predicted results are in good agreement with them in terms of trends and values. $\mathrm{k}-\mathcal{E}$ standard turbulence model has been selected as turbulence model, the PDF/Mixture Fraction combustion model and P-1 radiation model have been used for three-dimensional modellings. According to the predicted results, it has been revealed that steam addition into the oxidizer has decreased the predicted temperature values of coke oven gas. When the results are evaluated in terms of emissions, it has been found out that steam addition into the oxidizer has increased CO emissions somewhat while it has decreased NOX emissions considerably and $\mathrm{CO} 2$ emissions somewhat. Therefore, it has been concluded that high NOX problem caused by the use of coke oven gas being an alternative fuel can be overcome via steam addition into the oxidizer.
\end{abstract}

\section{GİRIŞ (INTRODUCTION)}

Enerji, günümüzün en önemli araştırma konuları arasında yer almaya devam etmektedir. Çünkü enerji, insanoğlunun varoluşundan günümüze kadar her zaman bir ihtiyaç olmuştur. Gelişen teknoloji ve artan nüfus ile birlikte enerjiye olan ihtiyaç da giderek artmakta olup bu durum da enerji kaynaklarının kullanımına olan yönelimi arttırmakta, bu nedenle de mevcut fosil enerji kaynakları hızla tükenmektedir. Doğalgaz ve petrol gibi fosil enerji kaynakları için bilim adamları tarafından öngörülen tükenme süreleri yüzyılı aşmamaktadır. Ayrıca, bu fosil enerji kaynaklarının Dünya üzerindeki dağılımı, başka sosyoekonomik ve siyasal problemleri de beraberinde getirmektedir. Ancak kömür için durum biraz daha farklıdır. Kömür, Dünya üzerinde nispeten daha adil bir şekilde yayılmıştır. Üstelik, kömür için öngörülen 
tükenme süresi en az 200 yıl olarak tahmin edilmektedir. Bu durumun da, kömürü orta vadede daha önemli bir enerji kaynağı haline getireceği düşünülmektedir [1].

Fosil yakıtlar, ihtiva ettikleri yüksek miktardaki enerjileri ile günümüzün en önemli enerji kaynakları olmaya devam etmektedirler (yaklaşık \% 85'ten fazla). Fosil yakıtların yakılması neticesinde açığa çıkan 1S1 enerjisi, bazı uygulamalar için doğrudan bazı uygulamalar içinse bir çevrim yardımı ile elektrik enerjisine çevrilerek kullanılmaktadır. Ancak, fosil yakıtların yakılması ile beraber, çevre ve insan sağlığını olumsuz yönde etkileyecek $\mathrm{CO}, \mathrm{CO}_{2}, \mathrm{NO}_{\mathrm{X}}, \mathrm{SO}_{\mathrm{X}}$ vb. bazı emisyonlar açığa çıkmaktadır. Özellikle kömürün yanması neticesinde yüksek seviyelerde $\mathrm{CO}, \mathrm{NO}_{\mathrm{X}}$ ve $\mathrm{SO}_{\mathrm{X}}$ salınımı gerçekleşmektedir. Dünya'daki bir çok ülke, bahsi geçen bu kirleticilerin seviyelerini azaltabilmek için bazı kısıtlamalara gitmekte, bu durum da bilim adamlarını daha temiz ve daha verimli yakıt eldesi sağlamaya ve yakma sistemlerini geliştirmeye itmektedir. Bunlardan birisi de, kömürün içerisindeki kirleticilerden kurtulmasını ve yüksek oranda karbon içeren kok eldesi için gerçekleştirilen koklaştırma işlemidir.

Kömürün koklaştırılması işlemi ile kok üretilirken aynı işlem neticesinde bir gaz da üretilir. $\mathrm{Bu}$ gaz, yoğuşabilir, aşındırıcı ya da ekonomik olarak değişken bileşenleri ayrıştırıldıktan sonra temiz bir gaz yakıt olarak elde edilebilmesi için ürün fabrikasında işlenir. Kok fırını gazı bünyesinde bir çok farklı bileşik bulunmakta olup hacimce \% bileşenleri şöyle sıralanabilir [2]:

Hidrojen $\left(\mathrm{H}_{2}\right)$

Metan $\left(\mathrm{CH}_{4}\right)$

Karbonmonoksit (CO)

Karbondioksit $\left(\mathrm{CO}_{2}\right)$

Nitrojen $\left(\mathrm{N}_{2}\right)$

Yüksek Parafinler ve Doymamış Hidrokarbonlar

Oksijen
$48-55$

$28-30$

$5,0-7,5$

$1,5-2,5$

$1,0-3,0$

$2,5-4,0$

$0,0-0,5$

Kok firını gazı, bünyesinden ihtiva ettiği bileşenler bakımından değerlendirildiğinde, özellikle hidrojen ve metan gibi yanabilir bileşenler toplamının \% 80'e yakın olması nedeniyle oldukça kaliteli bir gaz yakıt olduğunu anlaşılmaktadır. Ayrıca, kömürlerin gazlaştırılması ile elde edilen sentetik yakıtlara, içerikleri bakımından bazı farklılıklar gösterse de 5 ana bileşen $\left(\mathrm{H}_{2}, \mathrm{CH}_{4}, \mathrm{CO}, \mathrm{CO}_{2}\right.$ ve $\left.\mathrm{N}_{2}\right)$ bakımından da yakınlık göstermektedir [3]. Bu nedenle, bu çalışma için gerçekleştirilen literatür araştırmasında tüm gaz yakıtlar dikkate alınmış ve yapılan çalışmalardan bazıları aşağıda sıralanmıştır.

Asai vd. [4] tarafindan yapılan bir çalışmada hidrojence zengin yakıtların yanma esnasında meydana gelen dalgalanmaları kontrol altına alabilmek için çoklu-enjeksiyonlu bir yakıcı kullanılmış ve bu yakıtların yanma karakteristikleri araştırılmıştır. Çalışmada kullanılan dışbükey yakıcının bu yakıtların yakılmasında meydana gelen yanma kararsızlıklarını azalttığı sonucuna varılmıştır. Lee vd. [5] kömürkaynaklı sentetik yakıtların yanma karakteristiklerini gerçekleştirdikleri bir deneysel çalışma ile araştırmışlardır. $\mathrm{Bu}$ çalışmada, azot ile seyreltme yapılarak $\mathrm{NO}_{\mathrm{X}}$ emisyonlarının azaltılması hedeflenmiş ve yaklaşık 5 ppm'nin altına kadar da indirilebilmiştir. Lee vd. [6] tarafından gerçekleştirilen diğer başka bir çalışmada ise farklı içeriklere sahip sentetik yakıtların gaz türbini yanma şartlarında yanma ve emisyon karakteristikleri deneysel olarak araştırılmıştır. Lee vd. [7] bir başka çalışmalarında da bir önceki [6] çalışmalarında kullandıkları aynı gaz türbinini kullanarak farklı seyrelticilerin emisyonlara olan etkilerini araştırmışlardır. Elde ettikleri bulgulara göre en iyi seyreltmenin su buharı ile yapıldığı sonucuna varmışlardır. Habib vd. [8] tarafından gerçekleştirilen sayısal bir çalışmada ise paket tipi bir kazanda farklı içeriklere sahip sentetik yakıtların yanma ve emisyon karakteristikleri araştırılmıştır. Elde edilen veriler değerlendirildiğinde hidrojen oranı daha yüksek olan sentetik yakıtın alevinin daha kısa olduğu sonucuna varılmıştır. Göke vd. [9] ön-karışımlı bir yakıcıda doğalgaz-hidrojen karışımlı bir yakıtı 
kuru ve buharla seyreltilmiş oksitleyici koşullarında yakmışlardır. Elde edilen bulgulara göre, buharla seyreltmenin $\mathrm{NO}_{\mathrm{X}}$ emisyonlarının azaltılmasına önemli derecede katkı sağladığı belirlenmiștir. Tian vd. [10] ön-karışımsız bir yakıcıda yalnızca hidrojen, karbon monoksit ve karbon dioksitten karışımından oluşan bir sentetik yakıtı, nemli hava şartlarında yakmışlar ve nemli havanın yanma karakteristiklerine olan etkilerini deneysel olarak araştırmışlardır. Yapılan çalışma ile birlikte, hava içerisindeki nem oranı arttırıldıkça $\mathrm{NO}_{\mathrm{X}}$ emisyonlarının azaldığı tespit edilmiştir. Li vd. [11] gerçekleştirdikleri sayısal bir çalışma ile birlikte kısmi ön-karışımlı yanma şartlarında sentetik yakıtları $\mathrm{CO}_{2}$ ve $\mathrm{H}_{2} \mathrm{O}$ ile seyreltmişler ve bu seyreltmenin yanma ve emisyon karakteristiklerine olan etkilerini sayısal olarak araştırmışlardır. Yapılan modellemede LES (Large Eddy Simulation) tekniği kullanılmıştır. Elde edilen sonuçlara göre $\mathrm{CO}_{2}$ 'nin alev yapısını daha fazla etkilediği sonucuna varılmıştır.

Yukarıda, konuyla alakalı bazı çalışmalar sunulmuştur. Yapılan çalışmalar incelendiğinde, oksitleyicinin su buharı ile seyreltildiği ve bu seyreltmenin kok firını gazının yanma ve emisyon parametrelerine olan etkilerinin araştırıldığı bir çalışmaya rastlanmamaktadır. Karışım içeriği sonraki bölümlerde sunulacak olan kok fırını gazı, kuru hava şartlarında Ilbas ve Karyeyen [12] tarafından gerçekleştirilen bir çalışmada deneysel ve sayısal olarak yakılmış ve yanma ve emisyon parametreleri tarafından araştırılmıştır. Yapılan bu sayısal çalışmada ise, bu yakıt, $10 \mathrm{~kW}$ isıl güç ve 0,83 eşdeğerlilik oranı için gerekli minimum $\mathrm{O}_{2}$ miktarı değiştirilmeden, oksitleyici, bünyesinde hacimsel olarak \% 10, \% 20 ve $\% 30$ su buharı olacak şekilde seyreltilmiş ve bu seyreltmenin kok fırını gazı yanma karakteristiklerine olan etkisi sayısal olarak araştırılmıştır.

\section{SAYISAL MODELLEME (NUMERICAL MODELLING)}

Gaz karışımı yakıt yakma işlemi için tanımlanan matematiksel modellemeler, kararlı durum koşulu, üçboyutlu olarak süreklilik, momentum, enerji ve tür denklemlerine dayanmaktadır. Taşıma denkleminin genel formu şöyledir [13]:

$\frac{\partial(\rho \Phi)}{\partial x}+\operatorname{div}(\rho \Phi u)=\operatorname{div}(\Gamma \operatorname{grad} \Phi)+S_{\Phi}$

Burada $\Phi$ bağımlı değişkenleri temsil eder. $\Gamma, \Phi$ değişkeni için taşıma katsayısını, $S_{\Phi}$ ise $\Phi$ için taşıma denkleminin kaynak terimini belirtir.

$\mathrm{Bu}$ çalışmada, yanma modeli olarak Mixture Fraction / PDF Modeli kullanılmıştır. Bu yanma modelinde, her bir tür için taşıma denklemleri çözülmez. Onun yerine ilgili her bir türün konsantrasyonu, tahmin edilen karışım oranı alanlarından türetilir. Türbülans ve kimyanın etkileşimi, olasılıklu yoğunluk fonksiyonuyla (PDF) hesaplanır [14].

PDF model yaklaşımı, özellikle türbülanslı difüzyon alevlerinin simülasyonu için geliştirilmiştir. Yakıt/Oksitleyici sistemi için, karışım oranı $f$, yerel yakıt kütlesi oranı olarak şöyle ifade edilebilir:

$f=\frac{m_{F}}{m_{F}+m_{O}}$

Burada $m_{F}$ ve $m_{O}$, yakıt ve oksitleyici kütle oranlarını göstermektedir. 
Karışım oranı $f$, akış alanındaki her noktadaki değeri, türbülanslı akış alanının ortalama zaman değeri için aşağıdaki koruma denkleminin çözümü ile hesaplanan ve korunan bir miktardır [14].

$\frac{\partial(\rho \bar{f})}{\partial t}+\frac{\partial\left(\rho u_{i} \bar{f}\right)}{\partial x_{i}}=\frac{\partial}{\partial t}\left(\frac{\mu_{t}}{\sigma_{t}} \frac{\partial \bar{f}}{\partial x_{i}}\right)+S_{m}$

Burada $S_{m}$, yalnızca kütlenin, sıvı yakıt damlacıklarından gaz fazına transferi ile ilgili bir kaynak terimdir.

Ortalama karışım oranı için çözüme ek olarak, karışım oranı değişkeni için bir koruma denklemi çözülür. ${\overline{f^{\prime}}}^{2}$ türbülans-kimya etkileşimlerini tanımlayan kapanma modelinde kullanılır.

$\frac{\partial\left(\rho{\overline{f^{\prime}}}^{2}\right)}{\partial t}+\frac{\partial\left(\rho u_{i} \overline{f^{\prime}}\right)}{\partial x_{i}}=\frac{\partial}{\partial x_{i}}\left(\frac{\mu_{t}}{\sigma_{t}} \frac{\partial{\overline{f f^{\prime}}}^{2}}{\partial x_{i}}\right)+C_{g} \mu_{t}\left(\frac{\partial{\overline{f f^{\prime}}}^{2}}{\partial x_{i}}\right)^{2}-C_{d} \rho \frac{\varepsilon}{k}{\overline{f^{\prime}}}^{2}$

burada $\sigma_{t}, C_{g}$ ve $C_{d}$ Mixture Fraction/PDF modelinde kullanılan sabitlerdir.

Radyasyonla 1Sı transferi yüksek sıcaklıklarda gerçekleşir. Yanma odalarındaki, alev sıcaklığı, stokiyometrik yanma koşullarında genellikle yüksektir $\left(1000-1600{ }^{\circ} \mathrm{C}\right)$. Bundan dolayı, yanma işlemleri için radyasyon modelinin dahil edilmesi sıcaklık dağılımlarının daha doğru ve iyi tahmin edilebilmesine olanak sağlar [14]. P-1 modeli, daha genel P-N modelinin en basit örneğidir ve diğer radyasyon modellerine göre bazı avantajları vardır. Örneğin; P-1 modeli ile daha az bilgisayarcı işlemi ile daha etkin sonuçlar elde edilebilir. P-1 modeli, eğrisel koordinatlar içeren karmaşık geometrilere kolayca uygulanabilir [15]. Bu nedenle, bu çalışmada kok fırını gazının sayısal modellemesi ile yapılan sıcaklık ve emisyon tahmininin daha doğru sonuç vermesi için P-1 radyasyon modeli tercih edilmiştir.

\section{3. ÇALIŞMADA KULLANILAN YAKICININ ve YANMA ODASININ ÖZELLIKLERI (PROPERTIES OF THE BURNER and THE COMBUSTOR USED IN THE STUDY)}

$\mathrm{Bu}$ çalışmada kok firını gazı yakılmasında kullanılan oksitleyici su buharı ile seyreltilmiş ve bu seyreltmenin kok firını gazı yanma ve emisyon karakteristiklerine olan etkileri sayısal olarak araştırılmıştır. Çalışmada, Ilbas ve Karyeyen tarafından daha önce gerçekleştirilen bir çalışmada geliştirilen kok fırını gazı yakıcısı kullanılmış ve Şekil 1'de gösterilmiştir [12]. Bu yakıcı, ön-karışımsız bir yakıcı tipidir. Yakıcıda, yakıt ve oksitleyici eş merkezli olsa bile yakıt, yanma bölgesine eksenel olarak değil radyal olarak girmektedir. Yakıcının bu özelliği, yakıt ve oksitleyicinin daha iyi karışmasına ve daha kararlı alev oluşturulmasına yardımcı olmaktadır. Yakıcıda 2 farklı oksitleyici girişi bulunmaktadır. Bunlarda birisi, Şekil 1'de de gösterildiği gibi, oksitleyicinin $15^{\circ}$ 'lik bir eğimle yanma bölgesine dahil olmasını ve teğetsel hız etkisiyle daha kararlı bir alev oluşturmasını sağlamaktadır. Diğer oksitleyici girişi ise herhangi bir açı ile oluşturulmamış olup oksitleyici bu giriş ile yanma bölgesine yalnızca eksenel hız oluşturarak girmektedir. 




Şekil 1. Kok firını gazı yakıcısı

Şekil 2'de ise bu çalışmada kullanılan yanma odasının katı modeli sunulmuştur. Bu yanma odası, Ilbas ve Karyeyen [12] tarafindan daha önce gerçekleştirilen çalışmada deneysel olarak da kullanılmıştır. Bahsi geçen çalışmada elde edilen veriler ayrıca, bu çalışmada deneysel doğrulama için de kullanılmıştır. Yanma odasının üzerinde 5 adet ölçüm noktası bulunmaktadır. Bu çalışmada da bu ölçüm noktaları için elde edilen sayısal tahminler sunulmuştur. Yanma odasının dış yarı çapı $20 \mathrm{~cm}$, iç yarı çapı 19,8 cm, uzunluğu ise $1 \mathrm{~m}$ 'dir.

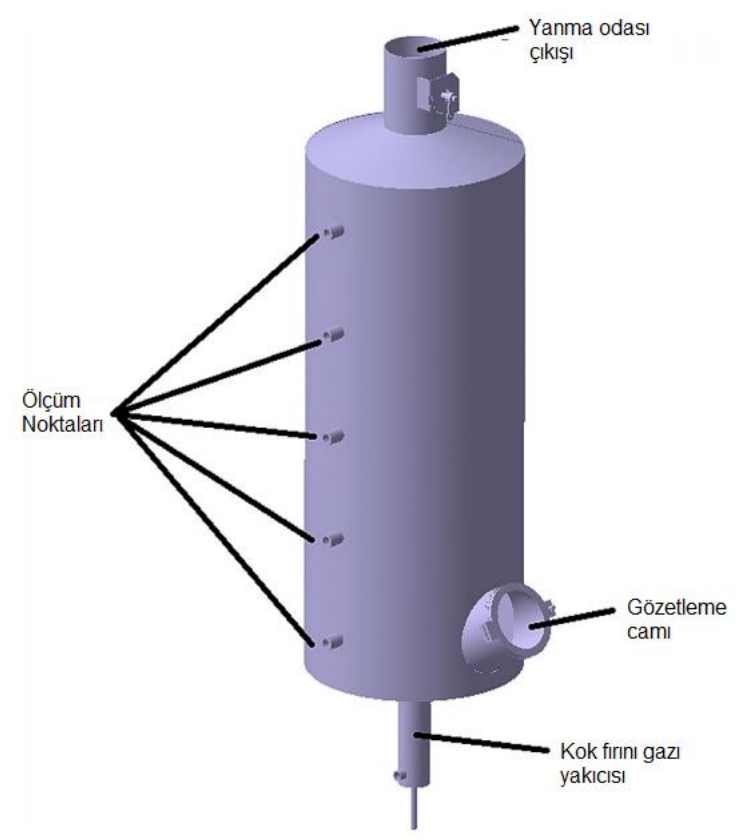

Şekil 2. Yanma odast

\section{SINIR ŞARTLARI (BOUNDARY CONDITIONS)}

Çalışmada kullanılan kok fırını gazının özellikleri Tablo 1'de gösterilmiştir. Kok fırını gazının sıcaklığı $293 \mathrm{~K}$ olarak belirlenmiş̧ir. Oksitleyici sıcaklığı ise su buharı ilavesinden dolayı $400 \mathrm{~K}$ olarak ayarlanmıştır. Kok fırını gazı ve oksitleyici basınçları ise atmosferik olarak belirlenmiştir. Ilbas ve 
Karyeyen [12] tarafından daha önce gerçekleştirilen ve kuru hava ile yapılan deneysel çalışmadan elde edilen verilerin bu çalışmanın doğrulanmasında kullanılabilmesi için tüm sayısal modellemelerde yanma odası dış duvarının $25^{\circ} \mathrm{C}^{\prime}$ lik bir ortamda olduğu kabul edilmiştir.

Tablo 1. Kok firını gazının özellikleri

\begin{tabular}{|l|l|}
\hline Kok Firinı Gazi & \% Hacimce \\
\hline $\mathrm{CH}_{4}$ & 27 \\
\hline $\mathrm{H}_{2}$ & 55 \\
\hline $\mathrm{N}_{2}$ & 10 \\
\hline $\mathrm{CO}_{2}$ & 2 \\
\hline $\mathrm{CO}$ & 6 \\
\hline
\end{tabular}

\section{SONUÇLAR ve TARTIŞMA (RESULTS and DISCUSSION)}

Sayısal çalışmalarda kullanılan akış hacminin hücrelere bölünmesi bilinmektedir. Bu çalışmada da yanma odası içerisindeki akış hacmi hücrelere ayrılmıştır. Ancak, sayısal çalışmalarda bilgisayarların çözüm zamanından kazanmak ve daha kısa sürede doğru sonuçlara ulaşmak için hücre sayısından bağımsızlaştırma işlemi yapılmasında fayda vardır. $\mathrm{Bu}$ nedenle, kok firını gazının yanma modellemelerine geçilmeden önce farklı hücre sayıları için modellemeler gerçekleştirilmiş ve bu modellemeler neticesinde elde edilen eksenel sıcaklık dağılımları Şekil 3’te gösterilmiştir. 238685 ve 260960 hücre sayılı modellemeler ile elde edilen eksenel sıcaklık dağılımlarında diğer hücre sayılı modellemeler neticesinde elde edilen eksenel sicaklık dağılımlarından daha farklı birer profil ortaya çıktığ 1 Şekil 3'ten anlaşılmaktadır. Ancak, 320894, 395844 ve 677086 hücre sayılı modellemelerde elde edilen eksenel sıcaklık dağılımları birbirine benzer sonuçlar olarak tahmin edilmiştir. 320894 hücre sayılı ağ yapısından daha fazla hücre sayısı içeren ağ yapılarını kullanmak bilgisayar çözümleme süresini uzatacağından ve anlamsız olacağından 320894 hücre sayısı içeren ağ yapısı, kok firını gazının sonraki modellemelerinde kullanılmak üzere seçilmiştir.

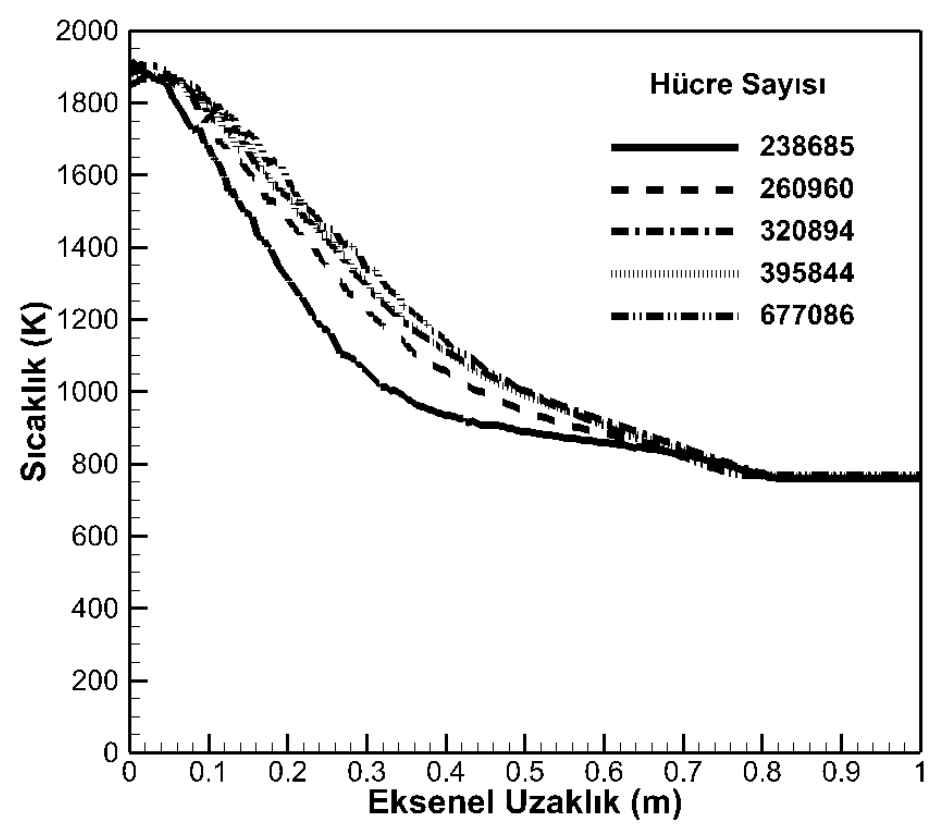

Şekil 3. Farklı hücre sayıları için eksenel sıcaklık dă̆glımları 
Şekil 4'te ise farklı türbülans modelleri için yapılan sayısal tahminler neticesinde elde edilen eksenel sıcaklık dağılımları sunulmuştur. Yapılan tahminler, Ilbas ve Karyeyen [12] tarafından kuru hava şartlarında gerçekleştirilen deneysel eksenel sıcaklık dağılımları ile karşılaştırılmıştır. Şekil 4 değerlendirildiğinde, 3 farklı türbülans modeli için de benzer eksenel sıcaklık dağılımlarının tahmin edildiği anlaşılmaktadır. Ancak yine de bazı ölçüm noktalarında k-E standard türbülans modeli ile yapılan tahminlerin deneysel verilerle daha iyi bir uyum içerisinde olduğu belirlenmiştir. Bu nedenle, uygun türbülans modeli olarak $\mathrm{k}-\mathcal{E}$ standard türbülans modeli seçilmiş ve sonraki modellemelerde bu türbülans modeli kullanılmıştır.

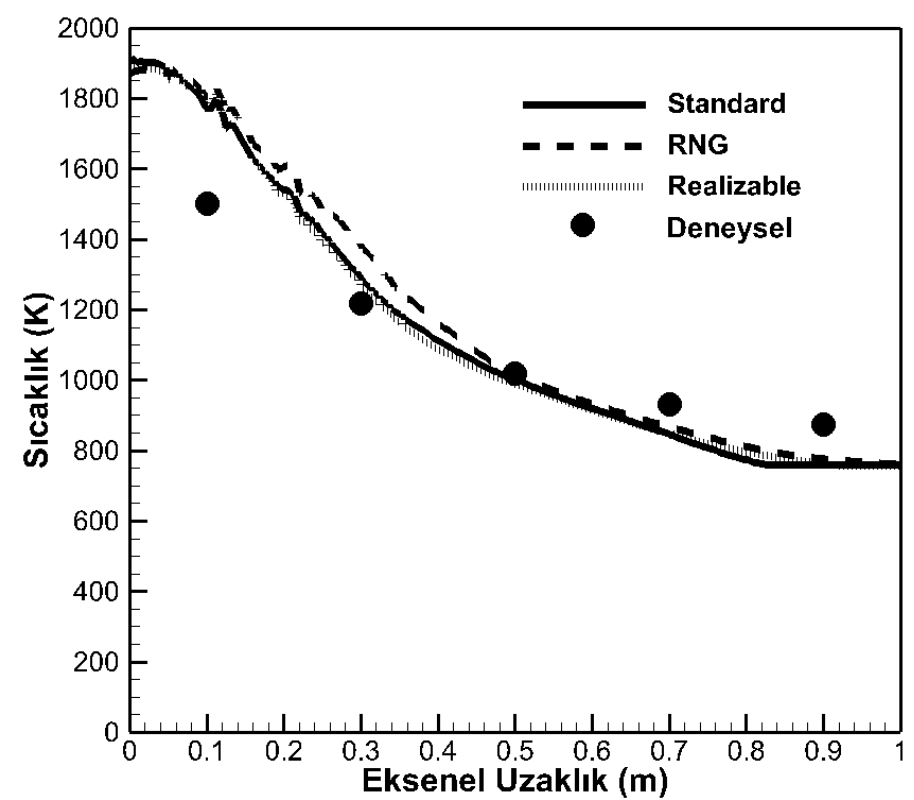

Şekil 4. Farklı türbülans modelleri ile gerçekleştirilen modellemeler için eksenel sıcaklık dağılımları 

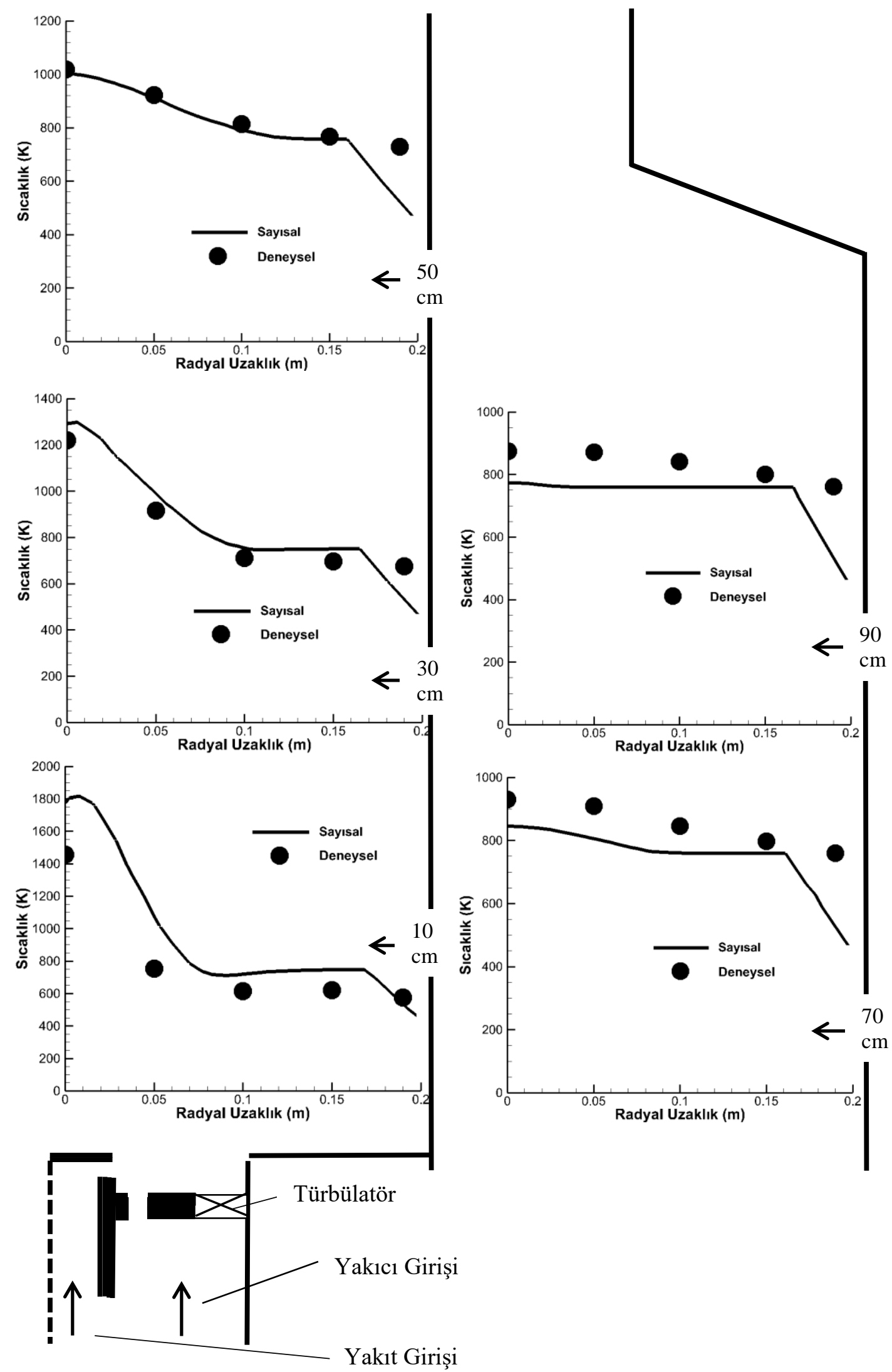

Şekil 5. Kok fırını gazı için elde edilen deneysel ve sayısal sıcaklık dağgllımlarının karşılaștırılması 
Kok fırını gazının yakılmasında kullanılan oksitleyiciye buhar ilavesinin yanma karakteristiklerini olan etkilerinin araştırıldığ 1 modelleme sonuçlarına geçilmeden önce, yapılacak modellemelerin doğruluğunun ortaya konulması gerekmektedir. Bu nedenle, Ilbas ve Karyeyen [12] tarafindan elde edilmiş deneysel sonuçlar kullanılmıştır. Bu deneylerde kok fırını gazı, oksitleyici olarak kuru hava kullanılarak aynı yakıcı, yanma odası ve sınır şartlarında yakılmıştır. Elde edilen radyal sıcaklık dağılımları, bu çalışma kapsamında, oksitleyici olarak kuru havanın kullanıldığ 1 modelleme tahminleri ile karşılaştırılmış ve Şekil 5'te gösterilmiştir. Şekil 5'ten de anlaşılacağ 1 gibi, yanma odası boyunca yapılan radyal sıcaklık tahminlerinin elde edilen deneysel verilerle dağılım, trend ve değer bakımından büyük ölçüde uyum içerisinde olduğu anlaşılmaktadır. Yanmanın modellenmesi birçok denklemin çözümünü gerektiren oldukça karmaşık bir işlemdir. Ayrıca, tahmini yapılan sıcaklık seviyelerinin de oldukça yüksek olması nedeniyle yapılan modelleme sonuçlarının deneysel verilerle tam bir uyum içerisinde olması da her zaman beklenmemektedir. Şekil 5'te gösterilen karşılaştırmalarda kabul edilebilir hataların olduğu da açıktır. Ancak yine de trend uyumunun büyük ölçüde sağlanmış olması sonraki modellemelerin de doğru olarak kabul edilebilmesi yeterlidir.

Kok firını gazı yanmasında kullanılan oksitleyicinin su buharı ile seyreltilmesi neticesinde elde edilen radyal sıcaklık dağılım tahminleri Şekil 6'da gösterilmiştir. İlk olarak, tüm yanma şartları için en yüksek sıcaklık seviyelerine alev bölgesinde ulaşıldığı tespit edilmiştir. Kuru hava şartları için tahmin edilen alev sıcaklığı değeri $1800 \mathrm{~K}$ civarında iken, oksitleyici bünyesindeki su buharı seviyesi arttırıldıkça bu değer, sırasıyla $1650 \mathrm{~K}, 1550 \mathrm{~K}$ ve $1400 \mathrm{~K}$ dolaylarında tahmin edilmiştir. Ardından, tüm yanma şartları için, 1şınımla ve taşınımla 1sı transferi etkileri nedeniyle yanma odası çıkışına doğru gidildikçe sıcaklık seviyelerinde azalmalar olduğu ve yapılan tahminler neticesinde yanma odası çıkışında kuru hava şartları için $800 \mathrm{~K}$ dolaylarında tahmin yapılırken diğer yanma şartlanı için sırasıyla yaklaşık $775 \mathrm{~K}, 750 \mathrm{~K}$ ve 725 K'lik yanma odası çıkış sıcaklığı tahminleri yapılmıştır. Yanma odası boyunca farklı ölçüm noktaları için elde edilen sıcaklık tahminleri değerlendirildiğinde, oksitleyiciye su buharı ilavesinin kok firını gazı yanma performansını bir miktar düşürdüğü, ancak azalma seviyelerinin $25 \mathrm{~K}$ ila $75 \mathrm{~K}$ arasında kaldığ tespit edilmiştir. Bu sonuç doğrultusunda, kok fırını gazı yanmasında buhar enjekte edilmiş oksitleyici kullanmanın kok fırını gazı yanma performanslarını önemli derede azaltmadığı sonucu çıkarılmışıır. 

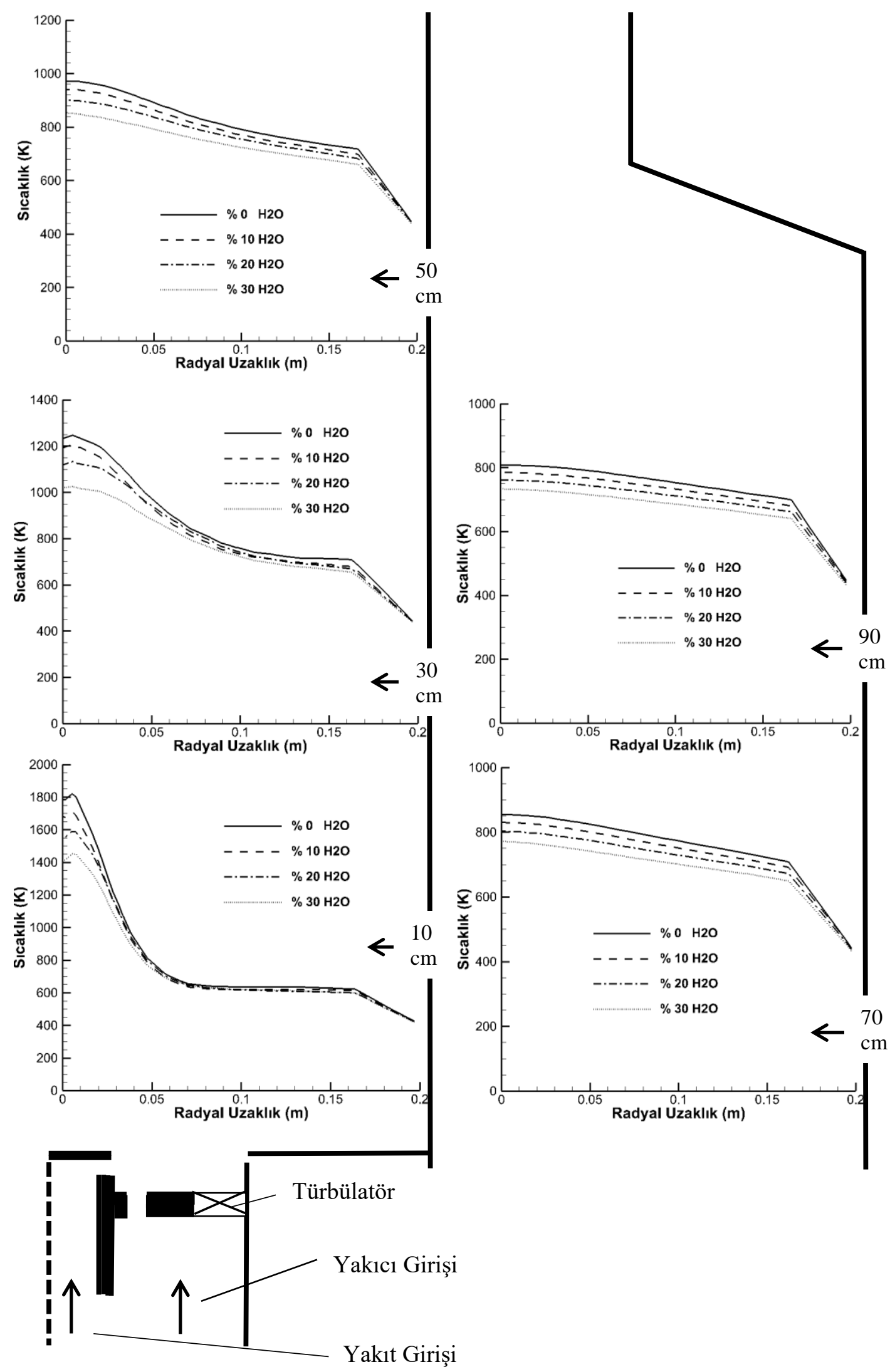

Şekil 6. Yakıcıya su buharı ilavesinin sıcaklık dağılımlarına olan etkisi 
Çalışmanın bu bölümünde ise kok firını gazı yanmasında kullanılan oksitleyicinin su buharı ile seyreltilmesinin yanma sonu emisyonlarına olan etkileri sunulmuştur. İlk olarak, Şekil 7'de Fluent programının $\mathrm{NO}_{\mathrm{X}}$-son işlemcisi ile tahmini yapılan radyal $\mathrm{NO}_{\mathrm{X}}$ dağılımları gösterilmiştir. Elde edilen sonuçlara göre, kuru hava ile gerçekleştirilen oksitleme işleminde yüksek $\mathrm{NO}_{\mathrm{x}}$ oluşumlarının ortaya çıktığı rahatlıkla söylenebilir. Yanma odası çıkışında kuru hava şartları için yaklaşık 200 ppm'lik $\mathrm{NO}_{\mathrm{X}}$ seviyesi tahmin edilmiştir. Burada, yakıt bünyesinde serbest olarak bulunan $\mathrm{N}_{2}$ 'un, tıpkı havada bulunan $\mathrm{N}_{2}$ gibi 1sıl $\mathrm{NO}_{\mathrm{X}}$ 'a katkı sağlaması önemli derecede rol oynamaktadır. Oksitleyicinin su buharı ile seyreltilmesi ile birlikte $\mathrm{NO}_{\mathrm{X}}$ seviyelerinde önemli derecelerde azalmalar olduğu da yine Şekil 7 'den anlaşılmaktadır. \% 10'luk bir seyreltme ile yanma odası çıkışındaki $\mathrm{NO}_{\mathrm{X}}$ seviyesi 50 ppm'nin altına inerken, \% 20 ve \% 30'luk seyreltmeler ile bu seviyeler yaklaşı 5 ppm ve 1 ppm seviyelerine kadar gerilemiştir. Sonuç olarak, $\mathrm{NO}_{\mathrm{X}}$ emisyonları bakımından değerlendirildiğinde kok fırını gazının yakılmasında kullanılan oksitleyicinin su buharı ile seyreltilmesi ile $\mathrm{NO}_{\mathrm{x}}$ emisyonu seviyelerinde önemli derecede azalma sağlandığı sonucuna varılmıştır.

Çalışma kapsamında $\mathrm{CO}$ ve $\mathrm{CO}_{2}$ emisyon tahminleri de yapılmış olup bu tahminlere ilişkin radyal dağılımlar Şekil 8 ve Şekil 9'da gösterilmiştir. Şekil 8 ve Şekil 9'u birlikte değerlendirmek daha doğru olacaktır. Çünkü $\mathrm{CO}_{2}$ emisyonlarının azalması $\mathrm{CO}$ emisyonlarının artması ile de açıklanabilmektedir. Oksitleyicinin su buharı ile seyreltilmesi neticesinde tüm yanma şartları için $\mathrm{CO}_{2}$ emisyonları bir miktar azalmış, buna karşın $\mathrm{CO}$ emisyonlarında bir miktar artış tespit edilmiştir. Oksitleyici bünyesinde bulunan ve teorik olarak yeterli olan $\mathrm{O}_{2}$ seviyeleri tüm yanma şartları için aynı olmasına ragmen bu sonuç, oksitleyici bünyesindeki su buharının, yakıttaki yanıcı bileşenlerden C'un oksitleyicideki yakıcı bileşen olan $\mathrm{O}_{2}$ ile buluşmasını ve tepkimeye girerek $\mathrm{CO}_{2}$ oluşturmasını bir miktar zorlaştırması ile açıklanabilir.

$\mathrm{Bu}$ çalışma kapsamında son olarak $\mathrm{H}_{2} \mathrm{O}$ emisyon tahminleri de yapılmış ve yanma odası boyunca elde edilen $\mathrm{H}_{2} \mathrm{O}$ tahminleri Şekil 10'da sunulmuştur. Şekil 10'dan görüleceği gibi oksitleyici bünyesindeki su buharı seviyeleri arttırıldıkça yanma odası içerisindeki su buharı seviyeleri de beklendiği gibi artmaktadır. Bunun yanı sıra, \% 10 su buharı içeren oksitleyici ile gerçekleştirilen yanma ile tahmin edilen $\mathrm{H}_{2} \mathrm{O}$ seviyesi yanma odası çıkışında yaklaşık \% 25 olarak tahmin edilirken, \% 20 ve \% 30 su buharı içeren oksitleyici ile gerçekleştirilen yanma neticesinde yapılan tahmin ile belirlene $\mathrm{H}_{2} \mathrm{O}$ seviyeleri aynı oranda yükselmemiştir. $\mathrm{Bu}$ durum da, kok firını gazı bünyesinde bulunan ve yanabilir bileşen olarak bilinen $\mathrm{H}_{2}$ 'nin, oksitleyici içerisindeki su buharı seviyesi arttıkça, oksitleyici bünyesinde bulunan $\mathrm{O}_{2}$ ile buluşmasının ve reaksiyona girmesinin biraz daha zorlaşması ile açıklanabilmektedir. 

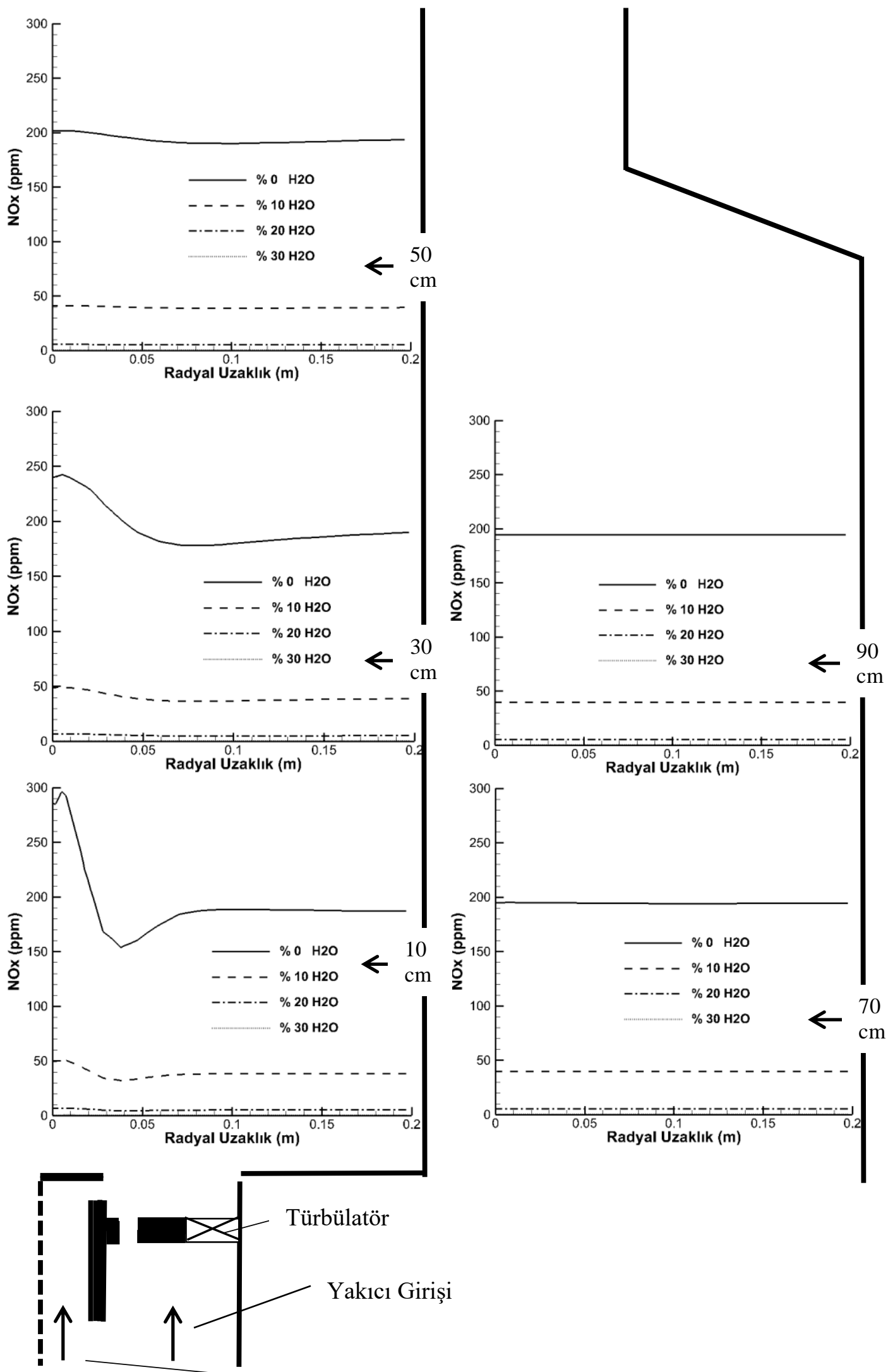

Şekil 7. Yakıcıya su buharı ilavesinin $N O_{X}$ dağılımlarına olan etkisi 

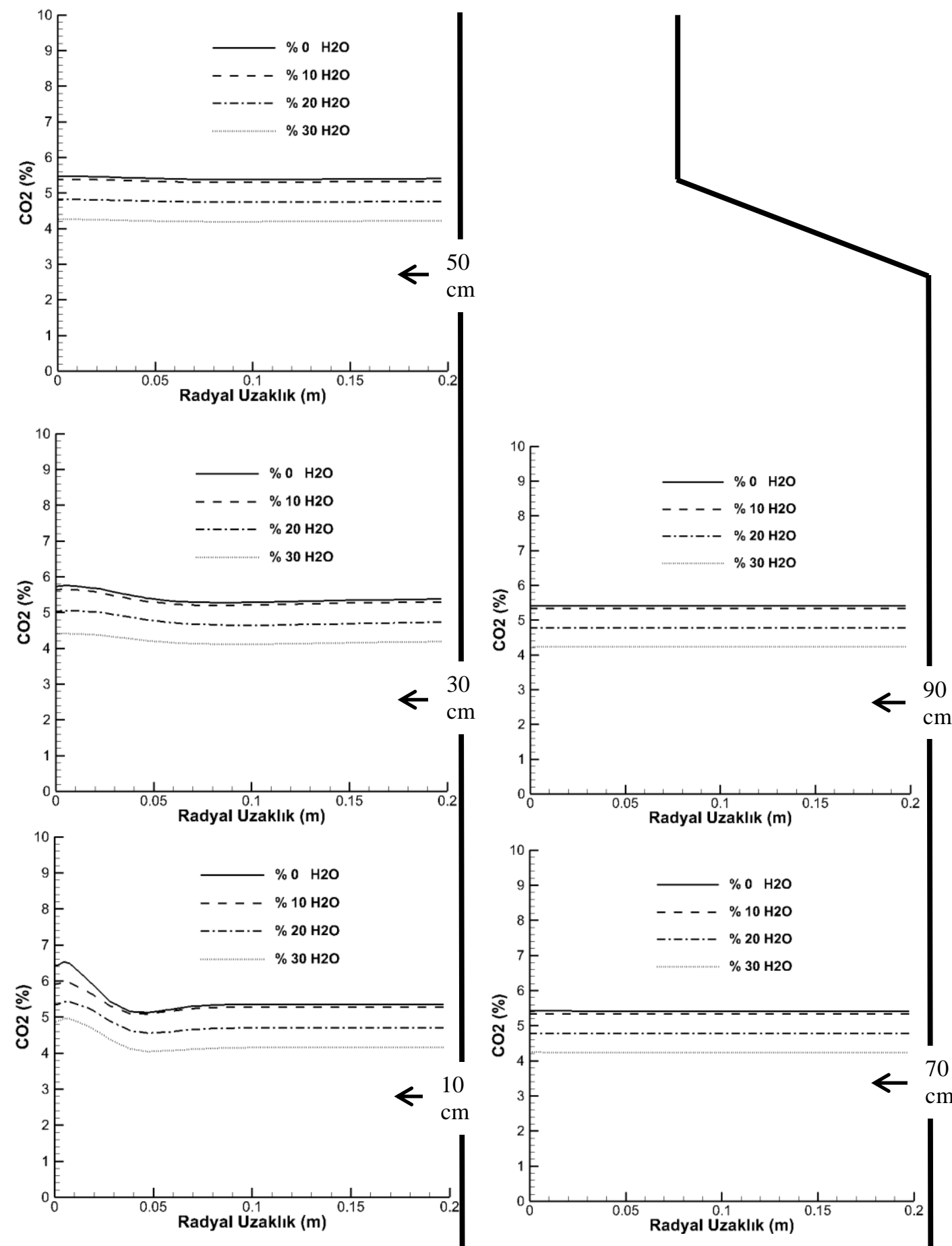

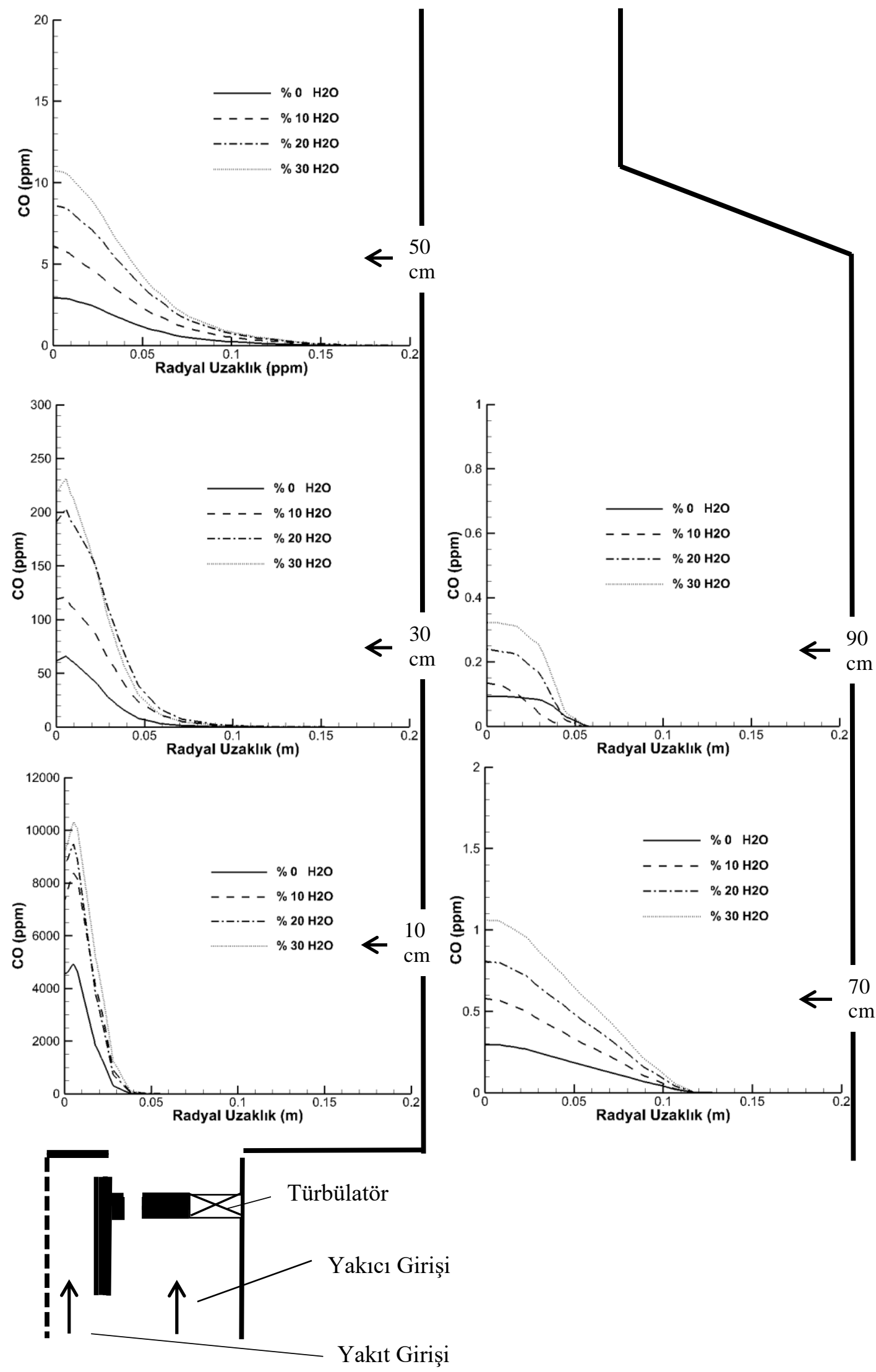

Şekil 9. Yakacıya su buhart ilavesinin CO dă̆glımlarına olan etkisi 

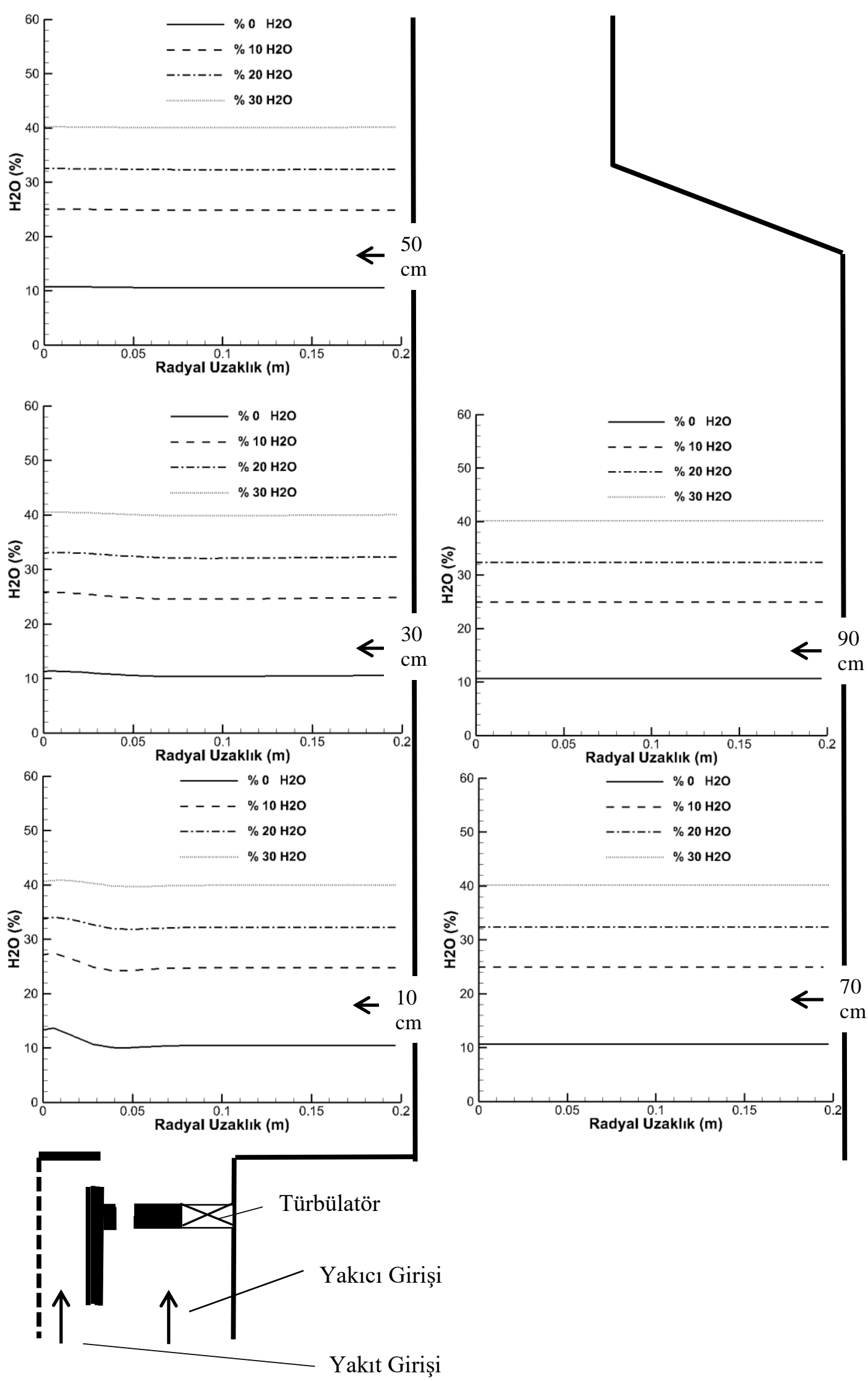

Şekil 10. Yakıcıya su buharı ilavesinin $\mathrm{H}_{2} \mathrm{O}$ dağılımlarına olan etkisi 


\section{SONUÇ (CONCLUSION)}

Bu çalışmada, kok firını gazının yakılmasında kullanılan oksitleyiciye su buharı ilavesi yapılmış ve bu ilavenin kok fırını gazının yanma karakteristiklerine olan etkileri sayısal olarak araştırılmıştır. Yapılan sayısal çalışmada ticari bir hesaplamalı akışkanlar dinamiği programı olan Fluent kullanılmıştır. Modellemeler üç boyutlu olarak gerçekleştirilmiş ve yanma sonu sıcaklık ve emisyon dağılımları sunulmuştur. Modellemeler ile yapılan tahminler neticesinde oksitleyiciye su buharı ilavesinin sicaklık seviyelerinde bir miktar azalmaya neden olduğu sonucuna varılmıştır. Buna karşın, oksitleyicinin su buharı ile seyreltilmesinin kok fırını gazının $\mathrm{NO}_{\mathrm{x}}$ emisyonlarını önemli derecede azalttı̆̆ tespit edilmiştir. $\mathrm{CO}_{2}$ emisyonlarında ise bir miktar azalma olurken $\mathrm{CO}$ seviyelerinde de bir miktar artış olduğu ortaya konulmuştur.

Elde edilen tüm sonuçlar değerlendirildiğinde kok firını gazının alternatif bir yakıt olarak kullanılabileceği, bu durumda ortaya çıkan yüksek $\mathrm{NO}_{\mathrm{X}}$ probleminin ise oksitleyici bünyesine su buharı ilavesi ile aşılabileceği sonucuna varılmıştır.

\section{TEŞEKKÜR (ACKNOWLEDGMENTS)}

Yazarlar, 114M668 nolu proje desteğinden dolayı Tübitak'a, Ansys Fluent yazılımının kullanımından dolayı Gazi Üniversitesi'ne teşekkür ederler.

\section{KAYNAKLAR (REFERENCES)}

[1] S. Karyeyen, Model bir gaz türbini yanma odasında kömür gazları yanma davranışının sayısal analizi, Yüksek Lisans Tezi, Ankara, Türkiye, 2013.

[2] K. Wright, Coke Oven Gas Treatment Tar, Liquor, Ammonia, The Coke Oven Managers' Year-Book, COMA (Coke Oven Managers Association), 2003.

[3] J. G. Speight, Synthetic Fuels Handbook: Properties, Process, and Performance, United States of America: The McGraw-Hill Companies, 2008.

[4] T. Asai, S. Dodo, H. Koizumi, H. Takahashi, S. Yoshida, H. Inoue, Effects of multiple injectionburner configurations on combustion characteristics for dry low $\mathrm{NO}_{\mathrm{X}}$ combustion of hydrogen-rich fuels, ASME 2011 Turbo Expo: Turbine Technical Conference and Exposition, 1-10.

[5] M. C. Lee, J. Yoon, S. Joo, Y. Yoon, Gas turbine combustion characteristics of $\mathrm{H}_{2} / \mathrm{CO}$ synthetic gas for coal integrated gasification combined cycle. International Journal of Hydrogen Energy, 40: (2015) $11032-11045$.

[6] M. C. Lee, S. B. Seo, J. H. Chung, S. M. Kim, Y. J. Joo, D. H. Ahn, Gas turbine combustion performance test of hydrogen and carbon monoxide synthetic gas. Fuel, 89: (2010) 1485-1491.

[7] M. C. Lee, S. B. Seo, J. Yoon, M. Kim, Y. Yoon, Experimental study on the effect of $\mathrm{N}_{2}, \mathrm{CO}_{2}$, and steam dilution on the combustion performance of $\mathrm{H}_{2}$ and $\mathrm{CO}$ synthetic gas in an industrial gas turbine. Fuel, 102: (2012) 431-438.

[8] M. A. Habib, E. M. A. Mokheimer, S. Y. Sanusi, M. A. Nemitallah, Numerical investigations of combustion and emissions of syngas as compared to methane in a $200 \mathrm{MW}$ package boiler. Energy Conversion and Management, 83: (2014) 296-305.

[9] S. Göke, M. Füri, G. Bourque, B. Bobusch, K. Göckeler, O. Krüger, S. Schimek, S. Terhaar, C. O. Paschereit, Influence of steam dilution on the combustion of natural gas and hydrogen in premixed and rich-quench-lean combustors. Fuel Processing Technology, 107: (2013) 14-22. 
[10] Y. Tian, S. Zang, B. Ge, Experimental investigation on the combustion performance of $\mathrm{N}_{2}$ dilution in syngas non-premix combustion in humid air conditions. Applied Thermal Engineering, 107: (2016) $560-564$.

[11] S. Li, S. Li, D. Mira, M. Zhu, X. Jiang, Investigation of dilution effects on partially premixed swirling syngas flames using a LES-LEM approach. Journal of the Energy Institute, https://doi.org/10.1016/j.joei.2017.09.005, In Press.

[12] M. Ilbas, S. Karyeyen, An experimental and numerical study on turbulent combustion of hydrogenrich coal gases in a generated non-premixed burner. Fuel, 194: (2017) 274-290.

[13] H. K. Versteeg, W. Malalasekera, An introduction to computational fluid Dynamics. Second Edition, PEARSON Prentice Hall, 2007.

[14] M. Ilbas, Studies of Ultra Low $\mathrm{NO}_{\mathrm{X}}$ Burner, PhD Thesis, Cardiff, UK: University of Wales, 1997.

[15] M. Ilbas $M$, The effect of thermal radiation and radiation models on hydrogen- hydrocarbon combustion modelling. International Journal of Hydrogen Energy, 30: (2005) 1113-1126.

[16] S. Karyeyen, Geliştirilen bir yakıcıda kömür gazlarının yanma karakteristiklerinin deneysel ve sayısal olarak araştırılması, Doktora Tezi, Ankara, Türkiye, 2016. 